\title{
Sero-Epidemiological Study of Respiratory Syncytial Virus
}

\author{
Mami Niida', Tetsuo Nakayama ${ }^{2 *}$, Eitaro Suzuki ${ }^{3}$ \\ ${ }^{1}$ Department of Pediatrics, Minami-Osawa Medical Plaza, Tokyo, Japan \\ ${ }^{2}$ Laboratory of Viral Infection, Kitasato Institute for Life Science, Tokyo, Japan \\ ${ }^{3}$ Suzuki Pediatric Clinic, Ube, Yamaguchi Prefecture, Ube, Japan \\ Email:mami-s@mua.biglobe.ne.jp, ${ }^{\star}$ tetsuo-n@lisic.kitasato-u.ac.jp, suzuki@bronze.ocn.ne.jp
}

How to cite this paper: Niida, M., Nakayama, T. and Suzuki, E. (2020) Sero-Epidemiological Study of Respiratory Syncytial Virus. Open Journal of Pediatrics, 10, 542-552.

https://doi.org/10.4236/ojped.2020.103055

Received: August 7, 2020

Accepted: September 22, 2020

Published: September 25, 2020

Copyright $\odot 2020$ by author(s) and Scientific Research Publishing Inc. This work is licensed under the Creative Commons Attribution International License (CC BY 4.0).

http://creativecommons.org/licenses/by/4.0/

\begin{abstract}
Background: Respiratory syncytial virus (RSV) is one of the major viruses that cause respiratory infections in all generations, not only in neonates and infants. There is a limited number of reports on serological epidemiology of RSV subgroups A and B. Neutralizing test (NT) antibody reflects protective immunity but bothersome. Sero-epidemiological study should be performed using practical NT method. Methods: Two wild-type viruses subgroups A and B, isolated in 2013, and the Long strain was used as the challenge viruses. NT antibody with $100 \%$ inhibition of cytopathic effect (CPE) was examined. A total of 91 serum samples obtained from 0 to 12 years subjects without RSV infection who visited our hospital with some health problems and 121 sera obtained from healthy subjects in different age groups were used. Serological epidemiology of subgroups A and B was investigated in this study using new NT methods. Results: 1) A simple and practical NT method was developed. 2) The NT antibody titer was lowest in $<1$ year of age $\left(5 \times 2^{1.70 \pm 2.03}\right.$ against subgroup A and $5 \times 2^{0.85 \pm 1.31}$ against subgroup B) and increased in 3 years of age or older, and high antibody titers were maintained during school age. 3) A slight difference was observed in the NT antibody titers against subgroups A and Bin young children $<3$ years, but not after 3 years of age, reflecting the repeated infections. 4) Specific IgG antibody against RSV was measured. The IgG EIA values decreased with age. No association was observed between IgG EIA and NT titers. Conclusions: A simple NT assay method was developed in the present study. By the age of 3 years, high NT antibody titers were observed and maintained until 12 years. The IgG (EIA) values decreased with age. No association was observed between IgG (EIA) and NT titers.
\end{abstract}

\section{Keywords}

RSV, Sero-Epidemiology, Neutralizing Antibody, IgG Enzyme Immunoassay 


\section{Introduction}

Respiratory syncytial virus (RSV) is a common viral pathogen for lower respiratory tract infection in infants and young children [1], and especially causes serious pneumonia and bronchiolitis in newborn infants with preterm, congenital heart diseases, and immunocompromised illnesses [2] [3] [4] [5]. RSV also causes lower respiratory infection in the elderly as well as young infants [6]. Almost $70 \%$ of children are infected with RSV by one year of age and approximately $100 \%$ by two years of age [1]. Repeat infections induce strong immunity, and thereafter it causes mild respiratory illness [1]. Previous studies showed that neutralizing antibody (NT) is related to immune memory to prevent serious lower respiratory tract infections [7]. Palivizumab, the specific neutralizing humanized monoclonal antibody, is used for prophylaxis in infants and young children with an increased risk of hospitalization due to serious complications of RSV [8]. Palivizumab is effective but expensive, with monthly administration during the outbreak season.

There are two subgroups, A and B, with different antigenic properties [9]. During an outbreak, several genotypes were found [10]. High levels of serum antibodies do not always prevent infection, and clinical reinfections with the same RSV subgroup were reported [11]. For subgroup A, at least ten genotypes (GA1-GA7, SAA1, NA1, and NA2) have been described, and recently ON1 with a 72-nucleotide insertion in the G genome was reported [12]. Like subgroup A, a 60-nucleotide insertion in the G genome was identified in subgroup B [13]. New genotypes have recently become dominant [14]. The antigenicity of new genotypes is of marked concern. It is necessary to examine NT antibody against each subgroup to evaluate the immunity.

RSV is a common pathogen, with an estimated 33 million patients with serious RSV infection in a year, 3 million hospitalizations, and 60,000 deaths in children aged $<5$ years globally [15]. However, there is no licensed vaccine at present. The development of a safe and effective RSV vaccine has been anticipated. A sero-epidemiological survey is required to evaluate the background of RSV immune status for the target generations for developing RSV vaccine. The neutralization test (NT) and enzyme immunoassay (EIA) have been employed in sero-epidemiological studies. NT is the most reliable method for evaluating vaccine immunogenicity, performing sero-prevalence studies, and detecting infection with a significant 4 -fold increase. However, NT test is time-consuming and troublesome experiment and requires skillful experience. The purpose of the study is to develop the sophisticated NT method and to perform serological epidemiology of subgroups A and B.

\section{Materials and Methods}

\subsection{Subjects}

We obtained 91 sera from patients aged 0 to 12 years who were hospitalized in Tama-Hokubu Medical Center from May to August 2014 with some medical 
problems, such as urinary tract infection, Kawasaki disease, asthma, and respiratory tract infections without detection of RSV using the rapid diagnosis kit. Patients with RSV infection and those with medical history of administration of palivizumab were excluded from the study.

A total of 121 sera of healthy children, consisting of approximately 10 subjects for each year of age, were previously obtained for serological investigation in different age groups to assess the serological background of vaccine preventable diseases. The purpose of the study was explained to the parents and written informed consent was obtained from all participants and their guardians. The Research Ethical Committee of Tama-Hokubu Medical Center approved this study, with the registration $25-18 / 2014$. The sera were stored at $-20^{\circ} \mathrm{C}$.

\subsection{Respiratory Syncytial Virus Strain}

The wild-type viruses were isolated from patients with a positive result using the rapid RS kit (check RSV ${ }^{\oplus}$ SA Scientific, Inc. San Antonio, Texas/ USA), and subgroups A and B were identified by genomic analysis. We assessed the genetic variability of RSV subgroups by restriction fragments analysis of PCR products and/or nucleotide sequence determination of part of the $\mathrm{N}$ protein gene [16]. We selected two clinical isolates in the epidemic period of 2013, representative of subgroups $\mathrm{A}$ and $\mathrm{B}$ as the challenge viruses.

\subsection{Virus Infectivity}

Infectivity was determined based on the $50 \%$ tissue culture infective dose $\left(\mathrm{TCID}_{50}\right)$ in Vero cells. The virus culture fluid was serially diluted by 10 -fold and a confluent monolayer of Vero cells was infected with $50 \mu \mathrm{L}$ of each dilution in 96-well plates in MEM supplemented with 2\% FBS. The plates were incubated for 7 days at $33^{\circ} \mathrm{C}$ in $5 \% \mathrm{CO}_{2}$.

\subsection{Enzyme Linked Immunosorbent Assay (EIA)}

Serum IgG antibodies against RSV (subgroup A) were measured by indirect EIA. The 96-well plate was coated with RSV (subgroup A) culture fluid overnight. After washing, the wells were blocked with Blocking One ${ }^{\oplus}$ (Nacalai Tesque, Kyoto, Japan). Serum samples were diluted at 1:200 and 100 $\mu \mathrm{L}$ was applied to the well. As the enzyme-conjugated secondary antibody, 1000-fold dilution of Anti Human-IgG $(\mathrm{H}+\mathrm{L})$ goat serum conjugated horseradish peroxidase (Gene Tex, Inc., Irvine, California/USA) was used. After washing and incubating the plate with the substrate solution, the reaction was stopped, and absorbance was read at $450 \mathrm{~nm}$ in a spectrophotometer.

\subsection{Neutralizing Antibody Titers (NT)}

NT antibody was measured based on the 100 percent inhibition of cytopathic effect (CPE). Serum samples were inactivated at $56^{\circ} \mathrm{C}$ for 30 mins and serially diluted by two-fold, starting from 1:10 dilution. They were mixed with an equal 
volume of the challenge virus containing 50 - $100 \mathrm{TCID}_{50}$. Fifty microliters of mixture were subsequently placed on the monolayer of Vero cells in a 96-well plate. The plate was incubated for 7 days and fixed with $95 \%$ ethanol. The plate was stained with goat anti-RSV polyclonal antibody (Abcam ${ }^{\circledast}$ Cambridge, England/UK) diluted to 1:1500, and then donkey anti-goat IgG antibody conjugated with horseradish peroxidase (Santa Cruz Biotechnology, Inc., Dallas, Texas/USA) diluted to 1:1500 was added. CPE was visualized using the Peroxidase Stain DAB kit with Metal enhancer for DAB staining (Nacalai Tesque, Inc., Kyoto, Kyoto/Japan). The NT titer is expressed as the reciprocal of the highest dilutions, which showed $100 \%$ inhibition of CPE.

\subsection{Statistical analysis}

Data analyses were done using Statcel 3 on Excel (OMS Publishing, Tokorozawa, Saitama/Japan). Serum IgG antibodies against RSV were analyzed using a simple regression analysis. Correlations were examined using Spearman's correlation coefficient by rank test.

\section{Results}

\subsection{Distribution of RSV Subgroups}

The distribution of RSV subgroups A and B was examined in 32 hospitalized patients in our hospital from July in 2013 to March in 2014. The results are shown in Figure 1. Subgroup A was detected in 12 (37.5\%), subgroup B in 17 (53.1\%), and $3(9.3 \%)$ were unidentified. The circulating strains have similar sequences for each subgroup. The circulating strains were conventional genotypes without insertion in the sequence, not a new one (ON1 or BA).

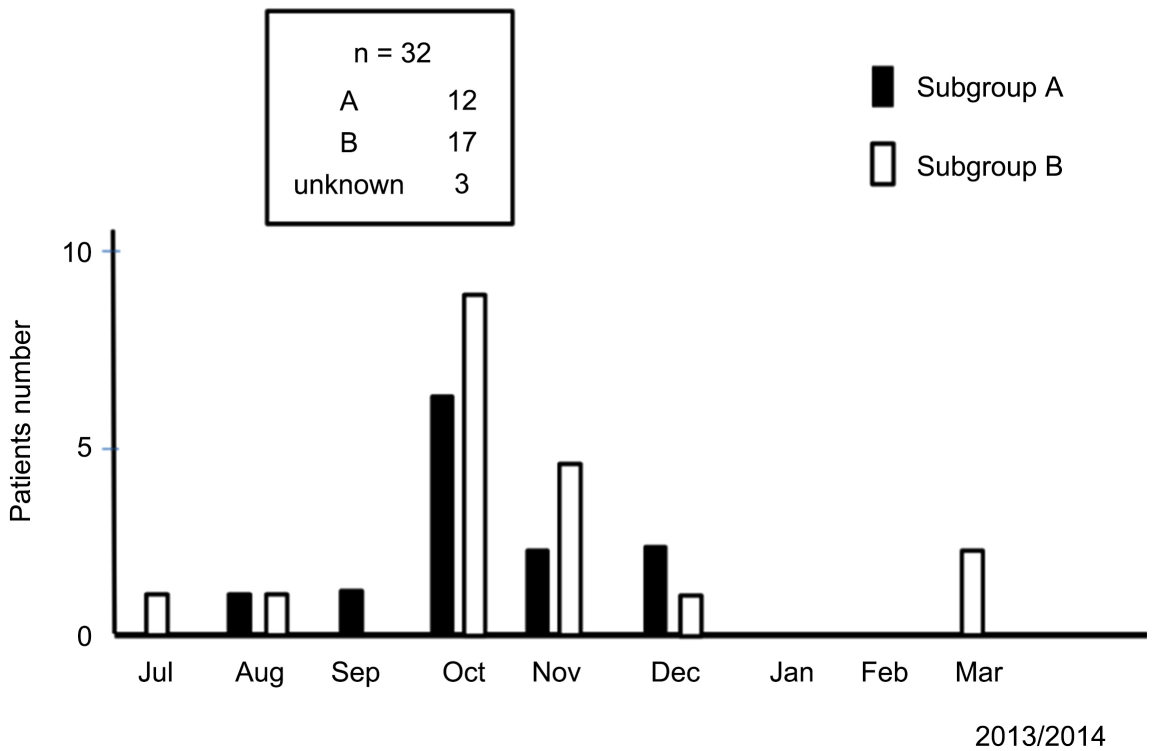

Figure 1. Distribution of RSV subgroups in Tokyo in the 2013/2014 season. Subgroups A and B were identified by restriction fragment length polymorphism and analyzed by nucleotide sequence determination of part of the $\mathrm{N}$ protein gene. 


\subsection{RSV EIA Antibodies in Healthy Children}

The results of IgG (EIA) antibodies against RSV (subgroup A) in 91 hospitalized patients without detection of RSV using the rapid diagnosis kit are shown in different age groups in Figure 2(a) and those of 121 healthy children in Figure 2(b). The IgG antibody titer decreased in the older age group. The regression lines of each group were as follows: IgG-0.02908 $\times$ age $+0.629549(\mathrm{p}=0.096)$ (Figure 2(a)), IgG $=-0.0466 \times$ age $+0.86832(\mathrm{p}=0.001)($ Figure $2(\mathrm{~b}))$.

\subsection{RSV NT Antibody in Healthy Children}

We developed an immunostaining method for the NT assay, and CPE was visible as black spots on a 96-well plate (Figure 3(a) and Figure 3(b)). The spots were confirmed as RSV-specific CPE by DAB staining, using anti-RSV monoclonal antibody (Figure 3(c)). The results of two serum examples (\#1 and \#2) are shown in Figure 3(a). Serum \#1 showed CPE at a 1:80 dilution and higher and the NT titer was determined as 1:40. Serum sample \#2 was negative. The complete inhibition NT antibody titers were examined.

The NT titers of 91 patients hospitalized without RSV infection against subgroups A and B are shown in Figure 4(a) and Figure 4(b), respectively. NT antibody titers are shown for each age (from 0 to 5 years) and the group from 6 to 10 years old. The mean antibody titer was lowest in $<1$-year infants (mean $\pm S D$ : $5 \times 2^{1.70 \pm 2.03}$ against subgroup $A$, and $5 \times 2^{0.85 \pm 1.31}$ against subgroup $B$ ) and the titer showed a higher level after 2 years of age. Mean NT antibody titers were lower against subgroup B than those against subgroup A.

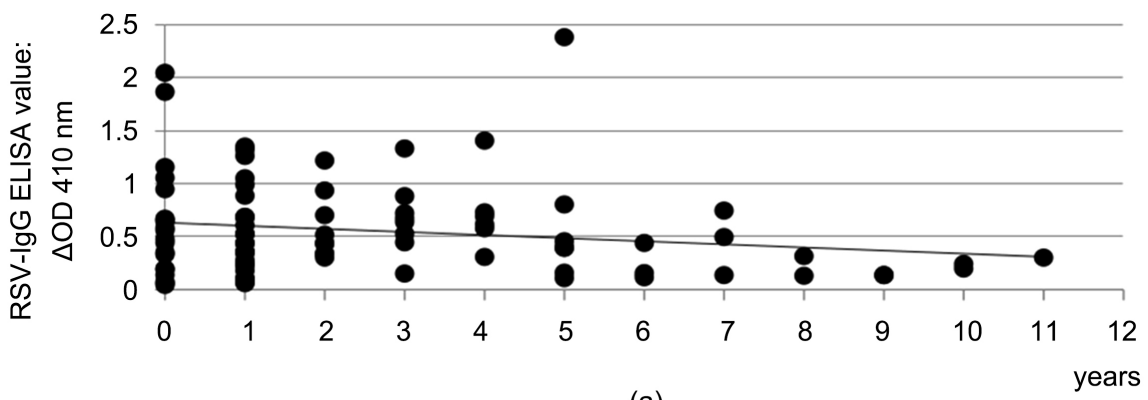

(a)

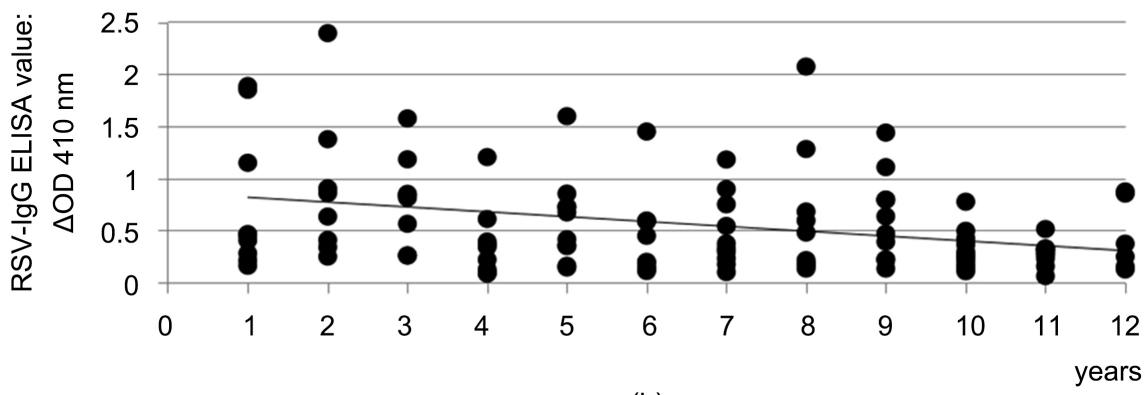

(b)

Figure 2. Serum IgG (EIA) antibodies against RSV at different ages. Dots show individual serum IgG (EIA) antibodies against RSV. (a) 91 patients hospitalized without RSV infection, (b) 121 healthy children. 


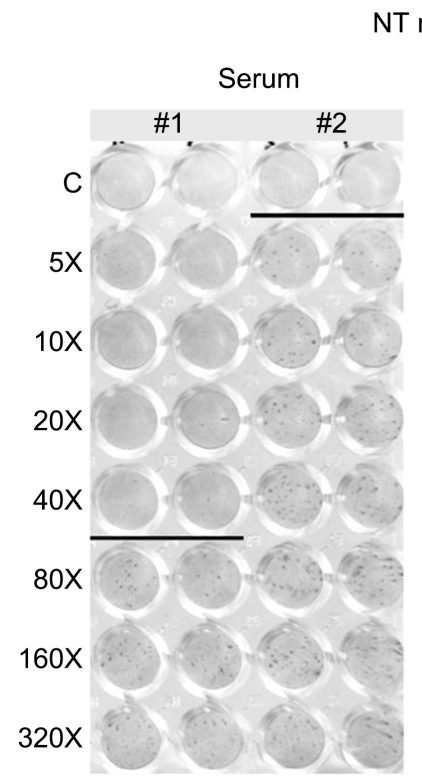

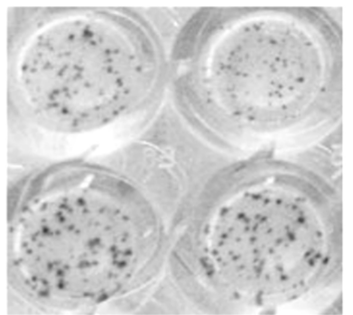

(b)

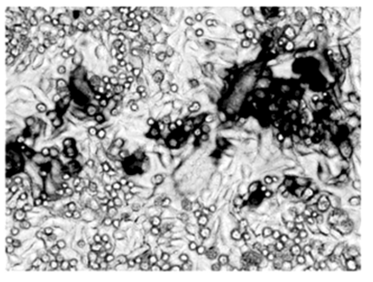

(c)

(a)

Figure 3. NT assay using immune staining. NT antibody titers were examined by complete inhibition of CPE. The black spots were confirmed as the DAB staining using goat anti RSV antibody and anti-goat IgG antibody raised in the donkey labelled with peroxidase. (a) Serum \#1 showed CPE at a 1:80 dilution and higher, the NT titer was 1:40, and \#2 was negative. (b) DAB staining of 96 -well plates. (c) CPE is magnified.

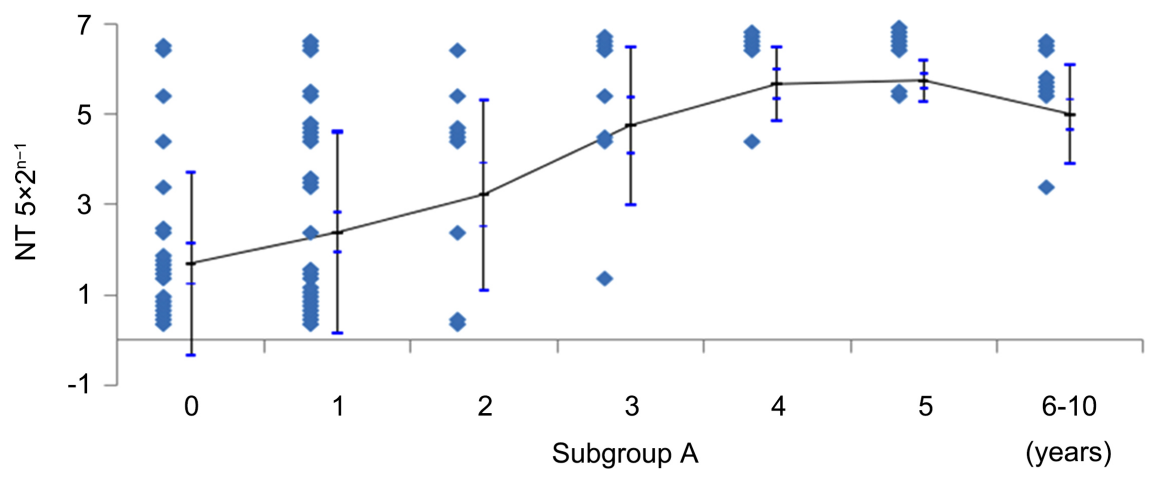

(a)

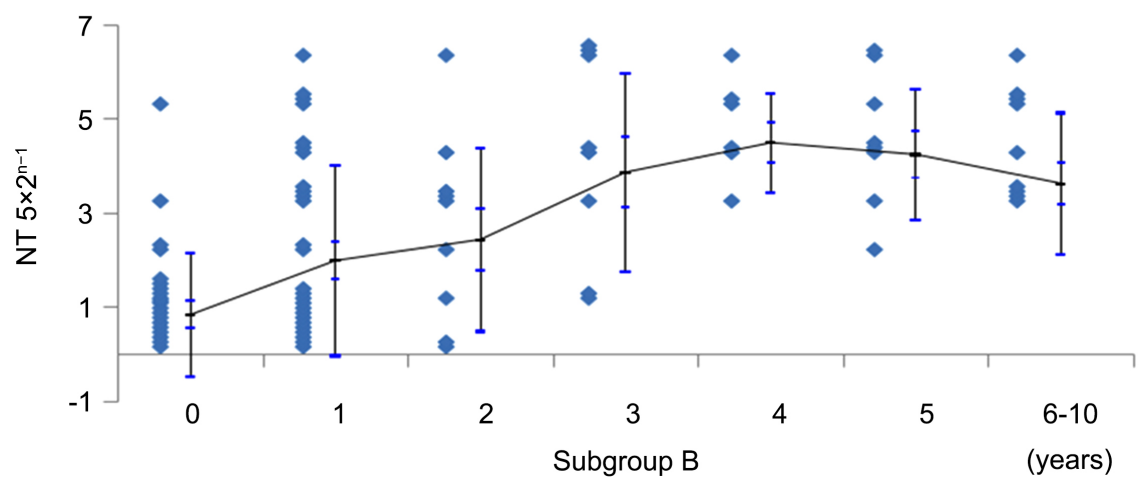

(b)

Figure 4. The NT antibody titer at different ages against subgroups A (upper panel) and B (lower panel) in 91 patients hospitalized without RSV infection. The dots indicate individual antibody titers, and bars indicate mean values with $1.0 \mathrm{SD}$. 
A total of 121 healthy children from 1 to 10 years old were examined. The change in NT titers against subgroups A and B is shown in Figure 5(a) and Figure 5(b), respectively. High NT antibody titers were observed at 3 years of age against both subgroups.

A moderate correlation was observed between NT titers against a circulating strain (wild subgroup A) and those against another circulating strain (wild subgroup B) with a correlation coefficient of 0.69 . However, there was lower correlation between NT titers against a circulating strain (wild subgroup A) and the Long strain $(r=0.35)$ (data not shown).

\section{Discussion}

The NT assay procedure is complicated and requires skillful experiences. The most time-consuming and critical stage of the test is the final observation of CPE under a microscope or counting the number of plaques. To simplify this step, CPE was visualized with the naked eye, using polyclonal antibody against RSV and a peroxidase staining kit. Spots developed with the peroxidase staining kit were easy to identify even by an untrained person, and we were able to accurately examine all wells in a short time, as with CPE determination under a microscope.

Using this NT test, serological surveillance was performed. The NT antibody titer was lowest in infants $<1$ year. There were few exposure opportunities due to being the pre-season or maternal conferred immunity. Even if they are infected,

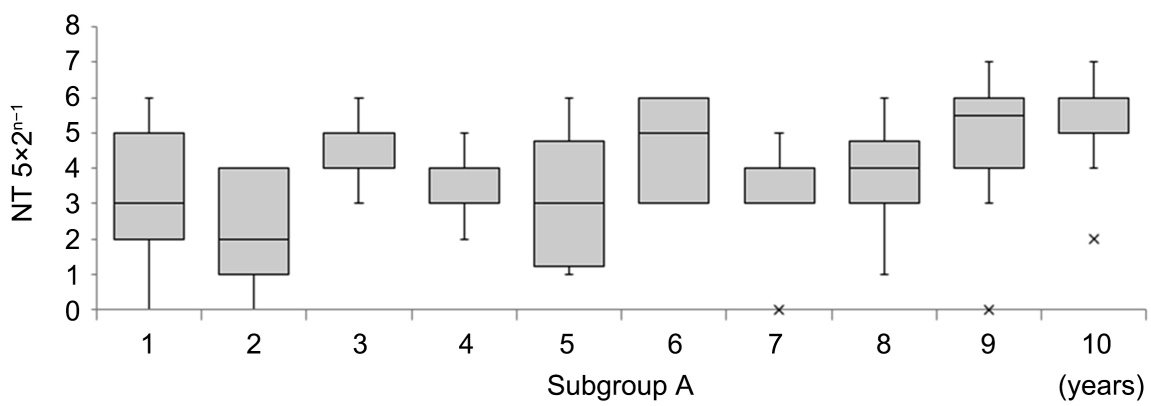

(a)

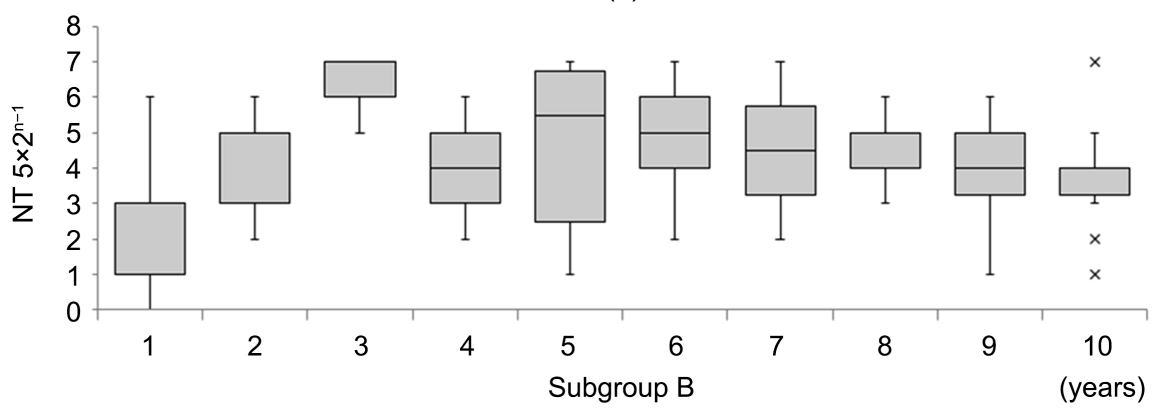

(b)

Figure 5. The neutralizing antibody titer with age against subgroups $\mathrm{A}$ and $\mathrm{B}$ in 121 healthy children. The antibody titers of NT against subgroups A (upper panel) and B (lower panel) are shown from 1 to 10 years old. Antibody responses are shown in box-and-whisker plots with the mean $\pm 1.0 \mathrm{SD}$. 
it is difficult for infants $<1$-year-old to show a sufficient antibody response because of the immaturity of acquired immune responses [17]. By the age of 2 years, repeat infections result in elevated antibody titers in most children. Children $>2$ years old produce durable antibodies and maintain high-level titers.

Children aged $<1$ year have conferred antibodies from the mother [18]. However, in this study, the neutralizing antibody titer was lowest in infants $<1$ year, since the mean \pm SD of the age in months in infants $<1$ year was $7.90 \pm 3.11$. Maternally derived specific antibodies declined and, therefore, the geometric mean titer was low. A more precise study is required to confirm the maternally conferred NT levels with decay caused by aging.

The antibody titers of IgG against RSV declined in older children. Generally, the severity of illness caused by RSV infection decreases in older children [19]. The antibody titers do not represent factors reducing the severity of infection. On the other hand, NT antibody titers were low in infants $<1$ year and titers rose after infancy. Only NT antibody is not associated with protective immune activity [20] [21], and we should examine nasal IgA antibody and cellular immunity. Repeat infections and exposure to RSV antigens induce strong immunity, but the cross-reactivity of the immune response against individual subgroup viruses has been inadequately elucidated [22]. The NT activity corresponds specifically to an individual virus, and cross-reactivity is observed in some viruses, such as RSV subgroups A and B [23]. It is important to possess sufficient levels of NT antibody against the latest circulating strains and those against the new genotypes need to be studied.

Cellular immunity is important, along with neutralizing activity, to prevent infection, but there is no practical method to assess the immunity in a clinical setting. A previous study showed that RSV-specific nasal IgA was more significantly correlated with protection than serum neutralizing antibody [24], but virus-specific IgA antibodies are shorter lived than serum IgG antibodies, being detectable for only a few months following infection [25]. Both serum and secretory antibodies are induced in response to RSV infection, even in young infants. However, the frequency and magnitude of the antibody response were significantly lower in young infants than in older infants and children [26]. Serum antibodies were low at younger than one year of age, even after the primary infection. Reinfection enhanced the antibody levels, and thus sustained the immunity [21].

The serum neutralizing antibodies to the G protein are RSV subgroup-specific [22]. In contrast, antibodies to the fusion (F) protein are cross-reactive between RSV subgroups [27]. It has been suggested that a weak response of antibody to $G$ protein of the heterologous group in the respiratory tract may determine reinfection with other RSV strains. The vaccines inducing both IgA and serum neutralizing antibody responses to the $\mathrm{F}$ protein are more protective and versatile.

To evaluate the efficacy of the vaccine, there is a need to conduct serological surveillance of protective antibody levels before vaccine use. Surveillance of 
whole populations is important, but there are no data on what level of neutralization activity is clinically effective. By examining children with different levels of severity depending on their age, it may be possible to deduce effective protection levels. Once a clinically effective level of neutralizing activity is known, it may be applicable as a surrogate marker of vaccine efficacy. To evaluate the usefulness of the vaccine in the future, it will be necessary to widely investigate the age-specific neutralizing antibody titer against each subgroup.

In conclusion, a simple and practical NT assay method was developed. NT titers were low in those $<1$ year of age and showed high levels after 3 years of age. NT titers against subgroup A were higher than against subgroup B.

\section{Funding}

TN received a research fund from Daiichi-Sankyo Pharmaceutical.

\section{Conflicts of Interest}

The authors declare no conflicts of interest regarding the publication of this paper.

\section{References}

[1] Glezen, W.P., Taber, L.H. and Frank, A.L. (1986) Risk of Primary Infection and Reinfection with Respiratory Syncytial Virus. American Journal of Diseases of Children, 140, 543-546. https://doi.org/10.1001/archpedi.1986.02140200053026

[2] Figueras-Aloy, J., Manzoni, P., Paes, B., Simões, E.A.F., Bont, L., Checchia, P.A., Fauroux, B. and Carbonell-Estrany, X. (2016) Defining the Risk and Associated Morbidity and Mortality of Severe Respiratory Syncytial Virus Infection among Preterm Infants without Chronic Lung Disease or Congenital Heart Disease. Infectious Diseases and Therapy, 5, 417-452. https://doi.org/10.1007/s40121-016-0130-1

[3] Paes, B., Fauroux, B., Figueras-Aloy, J., Bont, L., Checchia, P.A., Simões, E.A.F., Manzoni, P. and Carbonell-Estrany, X. (2016) Defining the Risk and Associated Morbidity and Mortality of Severe Respiratory Syncytial Virus Infection among Infants with Chronic Lung Disease. Infectious Diseases and Therapy, 5, 453-471. https://doi.org/10.1007/s40121-016-0137-7

[4] Checchia, P.A., Paes, B., Bont, L., Manzoni, P., Simões, E.A.F., Fauroux, B., Figueras-Aloy, J. and Carbonell-Estrany, X. (2017) Defining the Risk and Associated Morbidity and Mortality of Severe Respiratory Syncytial Virus Infection among Infants with Congenital Heart Disease. Infectious Diseases and Therapy, 6, 37-56. https://doi.org/10.1007/s40121-016-0142-x

[5] Manzoni, P., Figueras-Aloy, J., Simões, E.A.F., Checchia, P.A., Fauroux, B., Bont, L., Paes, B. and Carbonell-Estrany, X. (2017) Defining the Incidence and Associated Morbidity and Mortality of Severe Respiratory Syncytial Virus Infection among Children with Chronic Diseases. Infectious Diseases and Therapy, 6, 383-411. https://doi.org/10.1007/s40121-017-0160-3

[6] Malosh, R.E., Martin, E.T., Callear, A.P., et al. (2017) Respiratory Syncytial Virus Hospitalization in Middle-Aged and Older Adults. Journal of Clinical Virology, 96, 37-43. https://doi.org/10.1016/j.jcv.2017.09.001

[7] Kawasaki, Y., Hosoya, M., Katayose, M. and Suzuki, H. (2004) Role of Serum Neu- 
tralizing Antibody in Reinfection of Respiratory Syncytial Virus. Pediatrics International, 46, 126-129. https://doi.org/10.1046/j.1442-200x.2004.01860.x

[8] American Academy of Pediatrics Committee on Infectious Diseases; American Academy of Pediatrics Bronchiolitis Guidelines Committee (2014) Updated Guidance for Palivizumab Prophylaxis among Infants and Young Children at Increased Risk of Hospitalization for Respiratory Syncytial Virus Infection. Pediatrics, 134, 415-420. https://doi.org/10.1542/peds.2014-1665

[9] Anderson, L.J., Hierholzer, J.C., Tsou, C., Michael Hendry, R., Fernie, B.F., Stone, Y. and McIntosh, K. (1985) Antigenic Characterization of Respiratory Syncytial Virus Strains with Monoclonal Antibodies. Journal of Infectious Diseases, 151, 626-633. https://doi.org/10.1093/infdis/151.4.626

[10] Cane, P.A. and Pringle, C.R. (1995) Evolution of Subgroup a Respiratory Syncytial Virus: Evidence for Progressive Accumulation of Amino Acid Changes in the Attachment Protein. Journal of Virology, 69, 2918-2925.

https://doi.org/10.1128/JVI.69.5.2918-2925.1995

[11] Domachowske, J.B. and Rosenberg, H.F. (1999) Respiratory Syncytial Virus Infection: Immune Response, Immunopathogenesis, and Treatment. Clinical Microbiology Reviews, 12, 298-309. https://doi.org/10.1128/CMR.12.2.298

[12] Streng, A., Goettler, D., Haerlein, M., Lehmann, L., Ulrich, K., Prifert, C., Krempl, C., Weißbrich, B. and Liese, J.G. (2019) Spread and Clinical Severity of Respiratory Syncytial Virus a Genotype ON1 in Germany, 2011-2017. BMC Infectious Diseases, 19, Article No. 613. https://doi.org/10.1186/s12879-019-4266-y

[13] Fan, R.Y., Fan, C.P., Zhang, J., Wen, B., Lei, Y.F., Liu, C., Chen, L.J., Liu, W.P., Wang, C. and Qu, X.W. (2017) Respiratory Syncytial Virus Subtype ON1/NA1/BA9 Predominates in Hospitalized Children with Lower Respiratory Tract Infections. Journal of Medical Virology, 89, 213-221. https://doi.org/10.1002/jmv.24619

[14] Gaymard, A., Bouscambert-Duchamp, M., Pichon, M., et al. (2018) Genetic Characterization of Respiratory Syncytial Virus Highlights a New BA Genotype and Emergence of the ON1 Genotype in Lyon, France, between 2010 and 2014. Journal of Medical Virology, 102, 12-18. https://doi.org/10.1016/j.jcv.2018.02.004

[15] Shi, T., Mcallister, D.A., O’Brien, K.L., et al. (2017) Global, Regional, and National Disease Burden Estimates of Acute Lower Respiratory Infections Due to Respiratory Syncytial Virus in Young Children in 2015: A Systematic Review and Modelling Study. The Lancet, 390, 946-958. https://doi.org/10.1016/S0140-6736(17)30938-8

[16] Yui, I., Fujino, M., Sawada, A., et al. (2014) Novel Clinical Features of Recurrent Human Respiratory Syncytial Virus Infections. Journal of Medical Virology, 86, 1629-1638. https://doi.org/10.1002/jmv.23809

[17] Murphy, B.R., Graham, B.S., Prince, G.A., et al. (1986) Serum and Nasal-Wash Immunoglobulin $\mathrm{G}$ and a Antibody Response of Infants and Children to Respiratory Syncytial Virus F and G Glycoproteins Following Primary Infection. Journal of Clinical Microbiology, 23, 1009-1014. https://doi.org/10.1128/JCM.23.6.1009-1014.1986

[18] Walsh, E.E., Wang, L., Falsey, A.R., et al. (2018) Virus-Specific Antibody, Viral Load, and Disease Severity in Respiratory Syncytial Virus Infection. Journal of Infectious Diseases, 218, 208-217. https://doi.org/10.1093/infdis/jiy106

[19] Ohuma, E.O., Okiro, E.A., Ochola, R., Sande, C.J., Cane, P.A., Medley, G.F., Bottomley, C. and Nokes, D.J. (2012) The Natural History of Respiratory Syncytial Virus in a Birth Cohort: The Influence of Age and Previous Infection on Reinfection and Disease. American Journal of Epidemiology, 176, 794-802. 
https://doi.org/10.1093/aje/kws257

[20] Piedra, P.A., Jewell, A.M., Cron, S.G., Atmar, R.L. and Paul Glezen, W. (2003) Correlates of Immunity to Respiratory Syncytial Virus (RSV) Associated-Hospitalization: Establishment of Minimum Protective Threshold Levels of Serum Neutralizing Antibodies. Vaccine, 21, 3479-3482. https://doi.org/10.1016/S0264-410X(03)00355-4

[21] Hall, C.B., Walsh, E.E., Long, C.E., et al. (1991) Immunity to and Frequency of Reinfection with Respiratory Syncytial Virus. Journal of Infectious Diseases, 163, 693-698. https://doi.org/10.1093/infdis/163.4.693

[22] Sande, C.J., Mutunga, M.N., Medley, G.F., et al. (2013) Group- and Genotype-Specific Neutralizing Antibody Responses against Respiratory Syncytial Virus in Infants and Young Children with Severe Pneumonia. Journal of Infectious Diseases, 207, 489-492.

[23] Trento, A., Rodríguez-Fernández, R., González-Sánchez, M.I., et al. (2017) The Complexity of Antibody Responses Elicited against the Respiratory Syncytial Virus Glycoproteins in Hospitalized Children Younger than 2 Years. Frontiers in Microbiology, 8, 2301. https://doi.org/10.3389/fmicb.2017.02301

[24] Walsh, E.E. and Falsey, A.R. (2004) Humoral and Mucosal Immunity in Protection from Natural Respiratory Syncytial Virus Infection in Adults. Journal of Infectious Diseases, 190, 373-378. https://doi.org/10.1086/421524

[25] Green, C.A., Sande, C.J., De Lara, C., et al. (2018) Humoral and Cellular Immunity to RSV in Infants, Children, and Adults. Vaccine, 36, 6183-6190. https://doi.org/10.1016/j.vaccine.2018.08.056

[26] Sande, C.J., Mutunga, M.N., Okiro, E.A., et al. (2013) Kinetics of the Neutralizing Antibody Response to Respiratory Syncytial Virus Infections in a Birth Cohort. Journal of Medical Virology, 85, 2020-2025. https://doi.org/10.1002/jmv.23696

[27] Mcgill, A., Greensill, J., Marsh, R., et al. (2004) Detection of Human Respiratory Syncytial Virus Genotype Specific Antibody Responses in Infants. Journal of Medical Virology, 74, 492-498. https://doi.org/10.1002/jmv.20203 